\title{
Analytical Approaches in Glycobiology
}

\section{Mehta K$^{*}$ \\ Mehsana Urban Institute of Sciences, Ganpat University, India}

*Corresponding author: Kavit Mehta, Mehsana Urban Institute of Sciences, Ganpat University, Mehsana -Gandhinagar Highway, Ganpat Vidyanagar 384012, India, Tel: +919824698013; Email: kavitmehtabiotech@gmail.com

\section{Review Article}

Volume 3 Issue 1

Received Date: June 07, 2018

Published Date: July 06, 2018

DOI: $10.23880 /$ oajmb-16000125

\section{Abstract}

Glycobiology is a study of the structure, chemistry, biosynthesis, and biological functions of glycans and their derivatives. The high complexity of biomolecules necessitates a set of powerful analytical methodologies to reveal functionally critical structural features. Mass spectrometry (MS), with its different ionization techniques, mass analyzers, and detection strategies, has become the most important analytical method in glycomic and glycoproteomic investigations. In combination with MS, microscale separations are based on capillary chromatography and electrophoresis and carbohydrate microchemistry, In this article focuses on Analytical, methodological advances on disease biomarker research, immunology, developmental biology, and measurements of importance to biopharmaceuticals.

Keywords: Mass spectrophotometry; Capillary electrophoresis; Analytical

\section{Introduction}

According to Hart GW; Current opinion in cell biology (1992) [1] glycobiology is one of the great frontiers of biochemistry. The development of new technologies for exploring the structures of different sugar chains has opened up a new discipline of Analytical chemistry, Molecular biology and Bioinformatics, etc. is called as glycobiology. Horvath C, said how sweet it is sugar molecule then called as glycobiology. This term coined by Rademacher, Parekh, and Dwek (1988) to recognize the coming together of the traditional disciplines of carbohydrate chemistry and biochemistry with a modern understanding of the cellular and molecular biology of glycans [2-10].
The specific term glycobiology was coined in 1988 by Prof. Raymond Dwek to recognise the coming together of the traditional disciplines of carbohydrate chemistry and advance biochemistry. In fact, creating a cell requires two other major classes of molecules: lipids and carbohydrates. These molecules can serve as intermediates in generating energy, as signalling molecules, or as structural components [11-15]. The structural roles of carbohydrates become particularly crucial in constructing complex multicellular organs and organisms, which requires interactions of cells with one another and with the surrounding matrix. Indeed, all cells and many macromolecules in nature carry a dense and complex array of covalently attached sugar chains it called as oligosaccharides or glycans Feizi (1989) [16-21]. 


\section{Open Access Journal of Microbiology \& Biotechnology}

The scientific research community was practice in the development of the necessary tools transform into a roadmap of glycobiology. Glycan play vital role in growth and development and ageing process however glycan are likely to targeted discovery for biomarkers, vaccine and drug for cancer and inflammatory disease. In this article focused glycoscience needs new analytical techniques including method development for separation, purification, characterisation, localisation and structure identification [22-28].

Using analytical approaches newly developed technique the development of mass spectrophotometer, capillary electrophoresis, High-pressure liquid chromatography accumulated resources of the enzymatically synthesised compound to create new avenues for glycoscience [29-32].

\section{Fundamental Principle for Prediction of Glycan}

Sugar molecule linked to another type of biological molecule to form glycoconjugates. The enzymatic process of glycosylation creates sugar molecule bound to other particles by the glycosidic bond they producing glycan. Glycoprotein, proteoglycan, and glycolipid are the most abundant glycoconjugate found in mammalian cells. They are located predominantly in the outer cell wall and secreted fluids. It is essential in cell-cell interaction due to the presence on the cell surface of the various glycanbinding receptors to glycoconjugate. Glycan structure is also complicated by lack of a direct template for their biosynthesis in case with protein and lipid is determined by their corresponding gene. For accurate and advanced tool and technique for glycan structure prediction, one such technology is mass spectrometry are potent tools for characterizing complex carbohydrate [33-36].

\section{Analysis Approach}

A mixture of carbohydrate can be resolved into their component by many techniques such as differential centrifugation, ion exchange chromatography and gel filtration which are also used in protein and amino acid. Each glycan separated in the first stage of analysis is subjected to the following three analytical approaches for complete characterization.

1. Hydrolysis is firm acid yield mixture of monosaccharides which after conversion to suitable volatile derivative may be separated, identified and quantified by gas-liquid chromatography.
2. For the pure linear polymer, the position of the glycosidic bond between monosaccharide is determined by treating intact polysaccharide with methyl iodide to convert all free hydroxyl to acid stable methyl esters. When the methylated polysaccharide is hydrolysed, only free hydroxyl present in the monosaccharide produced is involved in glycosidic bonds.

3. To determine the stereochemistry at the anomeric carbon, the intact polymer is tested for sensitivity to purified glycosidases known to hydrolyse only $\alpha$ or only $\beta$ glycosides. Total structure determination for complex heteropolysaccharides is much more difficult. For degradation with highly specific glycosidase followed by isolation and identification of the product by mass spectral analysis and high-resolution NMR spectroscopy are highly powerful analytic tools for carbohydrate.

\section{Working Model of Glycobiology}

Glycobiology or glycomics is a discipline of biology and chemistry that deals with the structure and function of an oligosaccharide (chain of sugar). The term glycemic is derived from the chemical prefix for sweetness or sugar; "glyco". The identity of the entirety of carbohydrate in a cell, tissue or organism thus collectively referred to as the glycome.

To assume fact how creating a cell requires two other major classes of molecules lipid and carbohydrate. This molecule can serve as intermediates in generating energy as signalling molecules or structural components. The cell needs significant types of molecules like carbohydrates and fat.

In an actual way, these molecules can serve as intermediate in generating energy or structural elements. The fundamental roles of sugar molecule like carbohydrate become particularly crucial in complex multicellular organisms and organisms which require the interaction of the cell with another cell with surrounding matrix. All cell and many macromolecules in nature carry a dense and complex array of glycan. All cell and many other macromolecules covalently attached sugar chain of the molecule.

In some instances, these glycan molecules can be freestanding entities. Since most glycans are on the outer surface of cellular and secreted macromolecules, they are in a position to modulate glycome [37-39]. 


\section{Open Access Journal of Microbiology \& Biotechnology}

\section{Future Prospectus of Research}

It is a study of the structure, biosynthesis, and biology of sugar chain or glycan; Glycan is widely distributed in nature. This glycan is one of the more rapidly growing fields of basic research with relevance to medical science and biotechnology. These structure range from the chemistry of sugar chain and enzymology of glycan modifying the protein to the function of glycan in complex biological system and manipulation by a variety of technologies used several biotechnologies; pharmaceutical has invested in this area [40-42].

It is a study of the structure and biosynthesis of a sugar chain molecule essential component of various roleplay in the theraptic application in the biotechnological and medical field. As a result of an understanding of the cellular and molecular biology of glycan to better understand of sugar chain molecule used modern tool and technique for glycan molecule prediction.

\section{Conclusion}

Glycobiology is newer approaches to biotechnology. It is a combination of chemistry and Biotechnology to modifying the range of chemistry of sugar chain in complex biological system and manipulation by a variety of analytical techniques used in a therapeutic application in the biological sciences. As a understand phenomenon of cellular biology to the prediction of the molecule for therapeutical application in the field of pharmaceutical sciences.

\section{References}

1. Lennarz WJ, Hart GW (1994) Guide to techniques in glycobiology. Methods in Enzymology vol 230, Academic Press, San Diego.

2. MF Chaplin (1981) Biology of carbohydrates 1. In: Ginsburg V, Robbins P (Eds.), Wiley, New York.

3. Ginsburg V (1982) Complex carbohydrates part D. Methods in Enzymology 83: 3-684.

4. Ginsburg V (1987) Complex carbohydrates part E. Methods in Enzymology 138: 3-899.

5. Ginsburg V (1989) Complex carbohydrates part F. Methods in Enzymology 179: 3-639.

6. Ginsburg V, Robbins P (1991) Biology of carbohydrates 3, Wiley, New York.
7. Greiling H, Scott JE (1989) Keratan sulphate: Chemistry, biology, chemical pathology. The Biochemical Society, London.

8. Lane DG, Lindahl U (1990) Heparin: Chemical and biological properties, CRC Press, Boca Raton, Florida.

9. Fukuda M (1992) Cell surface carbohydrates and cell development, CRC Press, Boca Raton, Florida.

10. Bock K, Clausen H (1994) Complex carbohydrates in drug research: Structural and functional aspects. Munksgaard, Copenhagen.

11. Chaplin MF, Kennedy JF (1987) Carbohydrate analysis: A practical approach, IRL Press, Oxford.

12. Roth J, Rutishauser U, Troy F (1992) Polysialic acids. Birkhauser Verlag, Basel, Switzerland.

13. Conrad HE (1998) Heparin-binding proteins. Academic Press, San Diego.

14. Laurent TC (1998) The chemistry, biology and medical applications of hyaluronan and its derivatives, Portland Press Ltd, London.

15. Dumitriu S (2005) Polysaccharides-Structural diversity and functional versatility, Marcel Dekker, Inc, New York.

16. 16.

17. Wong CH (2003) Carbohydrate-based drug discovery, Wiley-VCH Verlag, Weinheim, Germany.

18. Wong SYC, Arsequell G (2003) Immunobiology of carbohydrates, Kluwer Academic/Plenum Publishers, New York.

19. Yarema KJ (2005) Handbook of carbohydrate engineering, CRC Press, Taylor and Francis Group, Boca Raton, Florida.

20. Lindhorst TK (2007) Essentials of carbohydrate chemistry and biochemistry $3^{\text {rd }}$ (Edn.), Wiley-VCH, Weinheim, Germany.

21. Fukuda M, Rutishauser U, Schnaar R (2005) Neuroglycobiology. Molecular and Cellular Neurobiology Series. Oxford University Press, Oxford.

22. Margolis RU, Margolis RK (1989) Neurobiology of glycoconjugates, Plenum Press, New York. 
23. Allen HJ, Kisailus EC (1992) Glycoconjugates: Composition, structure, and function, Marcel Dekker, Inc., New York.

24. Fukuda M (1992) Glycobiology: A practical approach, IRL Press, Oxford.

25. Varki A (1993) Analysis of glycoconjugates. In Current Protocols. In: F Ausubel, et al. (eds.), Molecular Biology Chapter 17, Green Publishing/Wiley Interscience, New York.

26. Montreuil J, Vliegenthart JFG, Schachter H (1997) Glycoproteins II. Elsevier, New York.

27. Townsend RR, Hotchkiss AT (1997) Techniques in glycobiology. Marcel Dekker, Inc., New York.

28. Montreuil J, Vliegenthart JFG, Schachter $\mathrm{H}$ (1996) Glycoproteins and disease, Elsevier, New York.

29. Gabius HJ, Gabius S, (1997) Glycosciences: Status and perspectives, Chapman and Hall, New York.

30. Brockhausen I (2006) Glycobiology protocols, Humana Press, Totowa, New Jersey.

31. Fukuda M (2006) Glycobiology. Methods in Enzymology 415, Academic Press, San Diego.

32. Fukuda M (2006) Glycomics. Methods in Enzymology 416, Academic Press, San Diego.

33. Sansom C, Markman O (2007) Glycobiology, Scion Publ. Ltd., Bloxham, United Kingdom
34. Fukuda M (2006) Functional glycomics. Methods in Enzymology 417, Academic Press, San Diego.

35. Taylor ME, Drickamer K (2003/2006) Introduction to glycobiology, Oxford University Press, United Kingdom.

36. Kamerling JP (2007) Comprehensive glycoscience, from chemistry to systems biology 1-4. Elsevier, Oxford.

37. Roberts DD, Mecham RP (1993) Cell surface and extracellular glycoconjugates: Structure and function, Academic Press, San Diego.

38. Fraser-Reid BO, Tatsuta K, Thiem J, Coté GL, Flitsch S, et al. (2008) Glycoscience-Chemistry and chemical biology I-III $2^{\text {nd }}$ (Edn.), Springer-Verlag, Berlin.

39. Hounsell EF (1998) Methods in molecular biology 76. Glycoanalysis protocols, Humana Press, Totowa, New Jersy.

40. Horowitz M, Pigman W (1982) The glycoconjugates, Academic Press, New York.

41. Alavi A, Axford JS (1995) Advances in experimental medicine and biology 376. Glycoimmunology, Plenum Press, New York.

42. Brockhausen I, Kuhns W (1997) Glycoproteins and human disease, RG Landes, Austin, Texas.

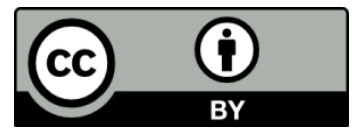

